This is a post-peer-review, pre-copyedit version of an article published in Geotechnical and Geological Engineering. The final authenticated version is available online at: http:// dx.doi.org/10.1007/s10706-020-01340-3 


\title{
INFRASTRUCTURE DAMAGE DUE TO DEWATERING WITHOUT CONSIDERING LAND USE HISTORY
}

\author{
Author 1 (Corresponding Author) \\ Ramesh Vandanapu, B.Tech, M.Tech, PhD, MIGS \\ Assistant Professor in Civil Engineering, Amity University, Dubai, U.A.E \\ ramesh.vandanapu@gmail.com \\ Author 2 \\ Joshua R. Omer, BSc (Hons.), MSc, PhD, MIEK, MDFI \\ School of Engineering and the Environment, Kingston University London, UK
}

\begin{abstract}
$\underline{\text { Abstract }}$
Geotechnical processes such as subsidence, seepage, scouring, extreme temperatures as well as geological events pose constructional challenges even despite advancements in design codes, ground investigation techniques and numerical analysis. This paper analyses a case record where subsidence and damages to existing structures occurred adjacent to a location where dewatering works were being carried out for a new pipeline. Initially, the damages were thought to be solely linked to the dewatering effects, but it was still a puzzle as to why the problems only occurred at particular locations and not over the entire dewatered area. To solve the puzzle, forensic ground investigation and geophysics were performed. Based on borehole and CPT results, the ground profile was interpreted and compared with results from two parallel geophysical methods. Both of these revealed that the problem area was part of an old channel that had been dredged decades earlier and reclaimed by filling with loose material. This was corroborated by theoretical calculations of ground subsidence, which was found to be consistent with values of 600-700 $\mathrm{mm}$ measured on site. This work therefore demonstrates the importance of thorough consideration of past site history as part of design of new works or analysis of dewatering effects on existing structures.
\end{abstract}

\section{$\underline{\text { Keywords }}$}

Geotechnical investigation, site history, case study, dewatering

\section{Introduction}

Of all engineering materials soils are probably the most challenging to model in rheological terms, being highly variable and subject to complex states of stress, phase changes, pore pressures, time-dependent processes and other effects (Tonks et al. 2017). Despite these challenges, evolutions in research, testing and computing technology have made it possible for soil behaviour to be predictable with greater and greater certainty, depending upon the level of investigations conducted. Furthermore, there are problematic soils such as expansive soils and collapsible soils which pose extra difficulties in geotechnical design and construction. Such soils may be able to support load when in the undisturbed insitu state but may behave radically differently under the influence of water, cyclic stresses, temperature changes etc. Some soft cohesive soils are highly responsive to changes in moisture hence prone to rapid settlement or swelling. Most clays exhibit gradual settlement with time when loaded whereas coarse granular soils generally undergo rapid settlement under load (Coduto 2010). Sands which are collapsible in nature have relatively high void sizes and open structures, so that when infiltrated by water such soils loose strength drastically, leading to structural distress or collapse (Rezaei et al. 2012). For all soil types, certain on-site operations such as dewatering create special problems notably settlement, tilt or even cracking of structures (Zumrawi and Hassan 2016). Dewatering causes stress re-distribution in the soils, changing the conditions from submerged to either saturated or dry state hence inducing settlement. This can cause eventual failure of the structure if precautions are not considered during the design stage (Samaaneh and Al-Gadhib 2013). The effects due to change in state of soil is adverse if very loose layers located at low depths are subjected to sudden increase in overburden pressure. Therefore to avoid problems in the latter stages, it is prudent to apply theoretical analysis to assess the anticipated ground settlement well in advance of the dewatering operation (Tan et al. 2014). This allows the theoretically calculated results to be corroborated with the field monitoring data (Charles 2008). Also, case records of both successful and failed projects may be used to supplement the observational approach, which is an increasingly popular method in geotechnical design (Ciria 1999). 
There are many construction projects worldwide where inadequate budget is allocated to the ground investigation stage, despite this being a crucial and challenging stage in many projects. An effective geotechnical investigation and where necessary supported by laboratory and field testing, can reduce risks and uncertainties (Tonks and Ameratunga 2012). Certain sites such as unstable fills and reclaimed land, if not properly investigated, can cause special risks leading to extensive structural failures. As pointed out by Tonks et al. (2017), reluctance by some clients to budget for proper geotechnical investigations can result in risks to them as well as to others. Post-construction problems linked to inadequate investigations usually will demand additional forensic investigations, which can impact the project cost and speed considerably. A typical case record of large scale infrastructure damage due to an unconsidered ground risk was presented by Vandanapu et al. (2016). A study conducted by Moorhouse and Millet (1994) on various case studies of failures showed that risks associated were not disclosed in approximately $40 \%$ of cases and also expert recommendations provided in geotechnical reports were not followed during construction. This technical note highlights a project where buildings, highway pavements and other structures suffered extensive damages as a result of dewatering activities in a certain area of the United Arab Emirates (UAE). The structural damages were largely concentrated along a stretch of land which was later detected as having previously been reclaimed from the sea and filled using unsuitable material.

\section{Case study}

Soon after dewatering works commenced at a certain location in the UAE, residents of adjacent areas started noticing significant and worsening defects and failures in buildings, road pavements and boundary walls. It was later discovered that the affected area was a reclaimed site forming part of an extensive flat sandy sabkha soil deposits subjected to tidal actions in the past. During high tides the soils became submerged and swampy but in low tides the soils were largely surface dry. During mid to late 1980s, dredging works were carried out in area and the dredged material placed as fill to raise the ground level. This material being unconsolidated marine deposits, proved to be poor for use as a fill material. The structural failures observed were of diverse types and occurred in different places and in different intensities. A small selection of the failures is illustrated in Figs. 1-3. Many boundary walls were cracked and tilted but some were overturned (Fig. 1). At some locations where boundary rested on continuous rigid beams, failure did not occur but the ground settled $200-250 \mathrm{~mm}$ as a consequence of the dewatering operations nearby. Severe cracking and subsidence in the range of 600-700 mm were noticed on flexible highway pavements. Pavement sections lying along the reclaimed site showed severe sag (Fig. 2) due sudden increase in overburden pressure on very loose soil below dewatered level. Some shallowly founded structures such as boundary walls and small outbuildings toppled (Fig. 3) and settlements of the order of 400-500 mm occurred in villas, paved areas and footpaths.

A geotechnical forensic investigation firm was engaged in order to investigate the causes of the problems, quantify the extent of the structural failures and recommend methods for reducing the adverse impacts. An important clue to the investigators was that the damages did not spread all over the dewatered site but rather were limited to the reclaimed section of a previously dredged channel. This is illustrated in Fig. 4, which identifies the stretch of road where the dewatering was carried out and the actual location of structural failures linked to dewatering. Particulars of the contract, client and consultants are not revealed here, due to client confidentiality and data protection reasons.

\subsection{Forensic investigations}

Forensic investigations involving both geotechnical and geophysical work sought to map out the failures, identify their causes and make recommendations for remedial measures. It was therefore imperative to explore the subsurface conditions and strata properties, particularly focusing on factors that could be linked to the structural failures.

\subsubsection{Geophysical Investigations}

In the geophysical survey, four lines were marked on the ground. Two of the lines were on either side of the structural failure area while the other two lines diagonally crossed the roadway lying over the dewatered area (Fig. 5). Geophysical investigations were carried out on each of the survey lines using two different methods namely Multichannel Analysis of Surface Waves (MASW) method and Electrical Resistivity Tomography (ERT). In the MASW technique, a surface wave was generated on the ground surface to travel through the ground at different depths before being refracted back to the surface. The 
In general, the MASW survey results showed distinct anomalies equating to relatively low shear wave velocities $\leq 200 \mathrm{~m} / \mathrm{s}$ for depths down to $3.0 \mathrm{~m}$ below the existing ground level. At this depth, the principal stratum was identified to be weak Sabkha soil. At particular locations within the structural failure area, the anomalies extended deeper $(7.5 \mathrm{~m}-8.5 \mathrm{~m}$ below ground surface) suggesting a possible correlation between the failures and the anomalies detected in the survey. A typical result of a survey line can be seen in Fig. 6.

Once MASW survey on all lines was completed, ERT survey was conducted on each survey line. The procedure for the ERT survey involved introducing an electrical potential difference between two electrodes arranged at predetermined intervals along the survey line. The spacing between electrodes corresponded to the depth interval investigated. The electric current resulting from the potential difference was recorded. The ERT technique enabled measurement of the resistivity of the ground, which could be correlated to relative density, strength and stiffness of the strata. Following Reynolds (1997), soil layers were inferred as loose if the resistivity values were greater than $10 \mathrm{ohm}-\mathrm{m}$. A sample ERT profile of a survey line can be seen in Fig. 7, wherein measurements were made to $25 \mathrm{~m}$ depth below ground (i.e. from reduced levels $103.800 \mathrm{~m}$ to $78.800 \mathrm{~m})$.

The results interpreted from the ERT survey corroborated well with those from the MASW surveys, hence giving confidence on the validity of the correlations. The zones of anomalies detected by both ERT and MASW surveys coincided remarkably with the structural failure areas. This close match lent credence to the suspicion that the affected site had been reclaimed from a dredged channel several decades in the past and filled with loose sandy soils.

\subsubsection{Geotechnical Investigations}

In order that the geophysical survey findings could be further verified and ground properties characterised, geotechnical investigations were carried out through 18 cone penetration tests (CPTs) taken to rock head level and 12 boreholes drilled to $20 \mathrm{~m}$ depths. All these investigations were carried out along the geophysical survey lines (Fig. 5). The investigation points were carefully selected so that the results from both borehole and CPTs could be used complementarily to determine the ground profile and strata properties. However, many more CPTs were undertaken than boreholes due to the rapidity of the CPT. Within the boreholes, standard penetration tests (SPTs) were carried out at every $0.5 \mathrm{~m}$ depth intervals from existing ground level (EGL) up to the bedrock level followed by coring of rock. Groundwater was encountered at an average depth of $2.40 \mathrm{~m}$ depth. Tables 1 and 2 present the general stratigraphy of the site as determined based on the borehole results from within and outside the structural failure zone. Results from boreholes and CPTs were separately used to interpret strata properties as well as soil profile differences between the locations inside and outside of the structural failure area (Table 3 ).

Very loose to loose soils, typically characterized by $\mathrm{N}<10$ and $\mathrm{q}_{\mathrm{c}}<10 \mathrm{MPa}$, were encountered at various locations (Table 3) both inside and outside of the structural failure area. Generally CPT results showed low $\mathrm{q}_{\mathrm{c}}$ values from $3.0 \mathrm{~m}$ to $4.0 \mathrm{~m}$ depths and also from $6.0 \mathrm{~m}$ to $7.0 \mathrm{~m}$ depths (this deep zone of low $\mathrm{q}_{\mathrm{c}}$ being consistent with the MASW and ERT results depicting the anomalies). Therefore, there was strong consistency between the results of different tests, all of which support the suspicion as to the genesis of the settlements and structural failures occurring in the area. In order to demonstrate the strata differences between areas inside and outside the predicted location of the dredged channel, values of SPT N and CPT $\mathrm{q}_{\mathrm{c}}$ were plotted against depth as shown in Figs. 8 and 9. These show that the thickness of the very loose to loose soils to be apparently larger within the structural failure area that outside of it. In addition, borehole 
logs showed that the thickness of the sandy fill material was considerably greater within the structural failure area than outside of it.

Along the four survey lines, ground settlements were calculated based on relative densities derived from both SPT and CPT data. There were significant increases in soil densities down to $6.0 \mathrm{~m}$ depth due to dewatering, implying increased overburden pressure acting on the deep loose soil layers. The calculated settlements were $893 \mathrm{~mm}, 656 \mathrm{~mm} *, 1176 \mathrm{~mm}$ and $1468 \mathrm{~mm}$ for lines 1, 2, 3 and 4 respectively. These values mirrored the typical measured settlements of $600-700 \mathrm{~mm}$ on site (Fig. 2). These findings consistently suggest a close relationship between the observed surface settlement, the presence of a deep loose fill (the reclaimed dredged channel) and the consequences of the dewatering activities.

* Sample Calculations for line-2

Considering borehole- 8 which was drilled in the structural failure area on line-2:

Depth of groundwater table $=2.80 \mathrm{~m}$

Water level after dewatering $=6.00 \mathrm{~m}$

Thickness of soil under consideration $(\mathrm{H})=6.00-2.80=3.20 \mathrm{~m}$

Relative density (RD) of soil before commencement of dewatering assumed to correspond to the loosest state. After dewatering, $\mathrm{RD}=40 \%$ as correlated from average of SPT N-values in $\mathrm{BH}-8$ within the zone of water level change)

For $\mathrm{RD}=40 \%$, Maximum dry density $=16.33 \mathrm{kN} / \mathrm{m}^{3}$ (from correlations)

Minimum void ratio, $\mathrm{e}_{\min }=\left(\mathrm{G} \gamma_{\mathrm{w}} / \gamma_{\max }\right)-1=(2.65 \times 9.81 / 16.33)-1=0.59$

From settlement theory, phase relationship consideration gives $\Delta \mathrm{H} / \mathrm{H}=\Delta \mathrm{e} /\left(1+\mathrm{e}_{0}\right)$

where,

$\Delta \mathrm{H}=$ change in thickness of soil layer

$\mathrm{H}=$ thickness of soil layer

$\Delta \mathrm{e}=$ change in void ratio

$\mathrm{e}_{0}=$ initial void ratio $=1\left(=\mathrm{e}_{\max }\right.$ for loosest state $)$

Total expected settlement, $\Delta \mathrm{H}=\mathrm{H}\left[\Delta \mathrm{e} /\left(1+\mathrm{e}_{0}\right)\right]$

$$
\begin{aligned}
& =\mathrm{H}\left[\left(\mathrm{e}_{\max }-\mathrm{e}_{\min }\right) /\left(1+\mathrm{e}_{\max }\right)\right] \\
& =3200[(1.00-0.59) /(1+1)] \\
& =656 \mathrm{~mm}
\end{aligned}
$$

\section{Possible solutions}

Upon completion and detailed analysis of the data from geophysical and geotechnical investigations, the following alternative solutions were suggested as plausible remedial measures:

\subsection{Permanent solution}

Given the type of soil and prevailing density values, it was suggested to perform ground improvement using techniques such as vibro-compaction or stone columns. The ground improvement works was to cover the 'right of way' of the road traversing the structural failure area and extending to a minimum of $25 \mathrm{~m}$ beyond the edges of the structural failure area. The improvement was to target a minimum RD of $70 \%$, confirmed by proof tests at randomly selected points, during the improvement process. It was further recommended:

(a) that no location was to have $\mathrm{RD}<65 \%$ and that overall an average $\mathrm{RD}=75 \%$ was to be achieved;

(b) to deploy SPT and CPT relative density measurement methods to verify ground performance post improvement;

(c) that to decide the improvement strategy (e.g. number of runs, spacing required, energy level needed), a trial area within the site was to be undertaken as a pilot study;

(d) that a regulation was to be enacted and enforced, requiring that any future dewatering activities do not cause ground settlements to adversely affect adjoining areas.

\subsection{Temporary solution}

A temporary solution was suggested whereby the damaged sections of the area to be excavated down to the groundwater table, followed by compaction of the underlying soil layers to at least $95 \%$ maximum dry 
density (MDD), installation of a tough geo-synthetic layer at the sub-grade level and finally reconstruction of the road pavement.

\subsection{Semi-permanent solution}

It was recommended to remove the failed parts of the road pavement lying just above the groundwater table, then compact stone layers to refusal followed by compaction (to not less than 95\% MDD) above the installed stone layer, laying a tough geo-grid layer on the sub-grade and reconstructing the pavement layers.

The aforementioned solutions could not be claimed to be permanent solutions since they did not include removal or improvement of the site anomalies. Therefore, until permanent solutions could be found, the underlying factors causing the settlement problem still existed and there was on-going risk of reoccurrence of future structural failures in the area.

\section{Conclusions}

The case study presented and analysed here demonstrates the absolute importance of giving thorough consideration to site history as part of ground investigations and recommendations for design and on-site operations such as dewatering works. Particularly for reclaimed land, both the medium term and long term effects of any site operations must be properly evaluated in advance. In places where developments are being undertaken in coastal or low lying areas, it is vitally important to consider the historical processes and development activities on and near the site, in order to minimise geotechnical risks to new future developments. This calls for information sharing and good record keeping for all projects so that complete historical site information is available to any interested party wishing to undertake new projects at any time. An appropriate way to achieve this is for Governmental authorities to make it a statutory requirement that developers submit comprehensive geotechnical information along with development plans for approval and secure filing to form a continuous national database.

\section{References}

Charles JA (2008) The engineering behaviour of fill materials: the use, misuse and disuse of case histories. Géotechnique, 58(7): 541-570. https://doi.org/10.1680/geot.2008.58.7.541

Ciria (Construction Industry Research and Information Association) (1999) Observational Method in Ground Engineering: Principles and Application, Ciria, London, UK, Report R185.

Coduto DP (2010) Geotechnical Engineering: Principles and Practices. Pearson Education, London, UK.

Moorhouse DC, Millet RA (1994) Identifying causes of failure in providing geotechnical and environmental consulting services. Journal of Management in Engineering, 10(3): 56-64. https://doi.org/10.1016/0148-9062\%2894\%2990015-9

Reynolds JM (1997) An introduction to applied and environmental physics. John Wiley and Sons, USA.

Rezaei M, Ajalloeian R, Ghafoori, M (2012) Geotechnical properties of problematic soils: emphasis on collapsible cases. International Journal of Geosciences, 3 (1): 105-110. http://dx.doi.org/10.4236/ijg.2012.31012

Samaaneh M, Al-Gadhib AH (2013) Modeling Impact of Dewatering on Soil Structure Interaction Using SAP. In: Proceedings of $9^{\text {th }}$ International Concrete Conference, Manama, Bahrain. https://www.researchgate.net/publication/271445768

Tan Y, Chen J, Wang J (2015) Practical investigation into two types of analyses in predicting ground displacements due to dewatering and excavation, Journal of Aerospace Engineering, 28(6): 1-10. https://doi.org/10.1061/(ASCE)AS.1943-5525.0000431

Tonks D, Gallagher E, Nettleton I (2017) Grounds for concern: geotechnical issues from some recent construction cases. Proceedings of Institution of Civil Engineers: Forensic Engineering, 170 (FE4):157-164. https://doi.org/10.1680/jfoen.17.00008

Tonks DM, Ameratunga J (2012) Trial embankments to reduce geotechnical risks on poor ground. In: Proceedings of the $11^{\text {th }}$ ANZ Conference on Geomechanics, Melbourne, Australia, 1473-1478.

Vandanapu R, Omer JR, Attom, MF (2016) Geotechnical case studies: emphasis on collapsible soil cases. Proceeding of the Institution of Civil Engineers: Forensic Engineering, 169(FE3): 103-110. http://dx.doi.org/10.1680/jfoen.16.00011

Zumrawi MME, Hassan E (2016) Effect of Excavation Dewatering on Adjacent Structures.University of Khartoum Engineering Journal, 6(2): 22-29. https://www.researchgate.net/publication/316279492 
Fig.1 Overturning of boundary wall of a villa

Fig.2 Cracking and extreme subsidence in pavement (settlement $\sim 600-700 \mathrm{~mm}$ )

Fig.3 Deformed boundary wall of a villa

Fig.4 Historical aerial image of mid 1980s

Fig.5 Distressed area and geophysical investigation lines (Lines 1-4)

Fig.6 MASW survey result (Line 4)

Fig.7 ERT survey result (Line 4)

Fig.8 Variation of SPT blow counts with depth (from drilled boreholes)

Fig.9 Variation of tip resistance with depth (from cone penetration tests)

\section{TABLE CAPTIONS}

Table 1 General stratigraphy of the site within the distressed area

Table 2 General stratigraphy of the site outside the distressed area

Table 3 Comparison of weak layers from CPT and borehole data (samples along lines $2 \& 4$ ) 


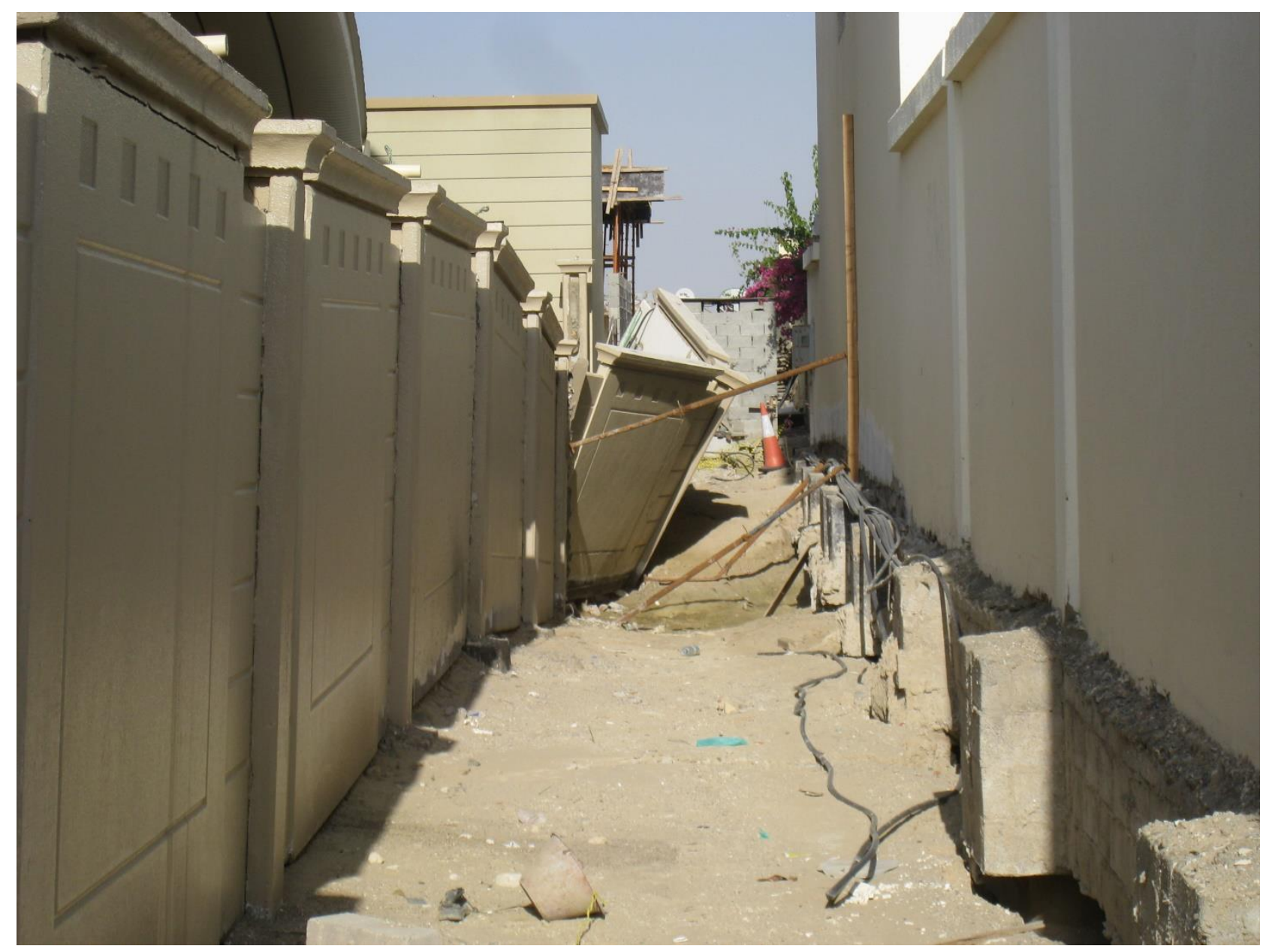

Fig.1 Overturning of boundary wall of a villa 


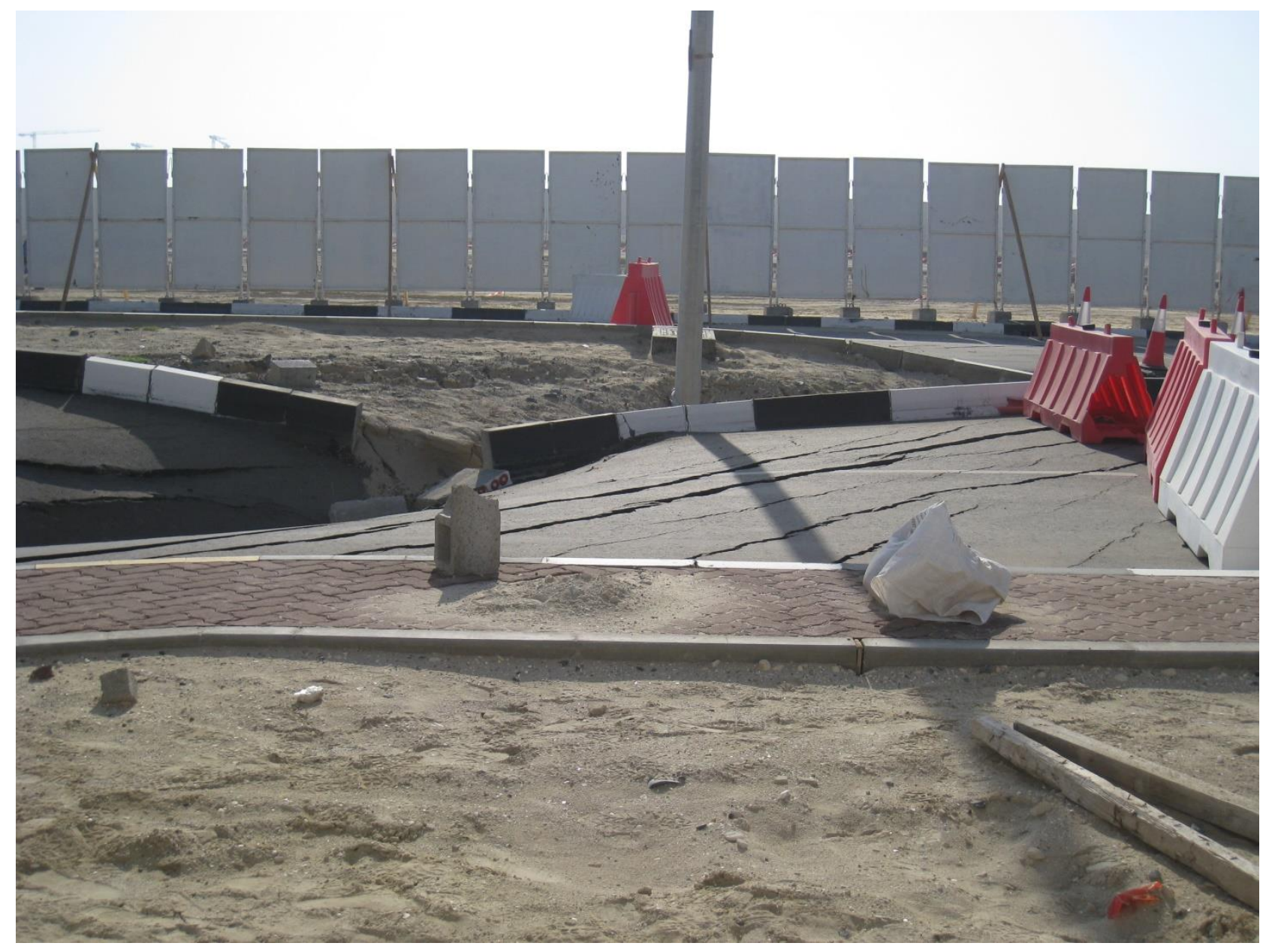

Fig.2 Cracking and extreme subsidence in pavement (settlement $\sim 600-700 \mathrm{~mm}$ ) 


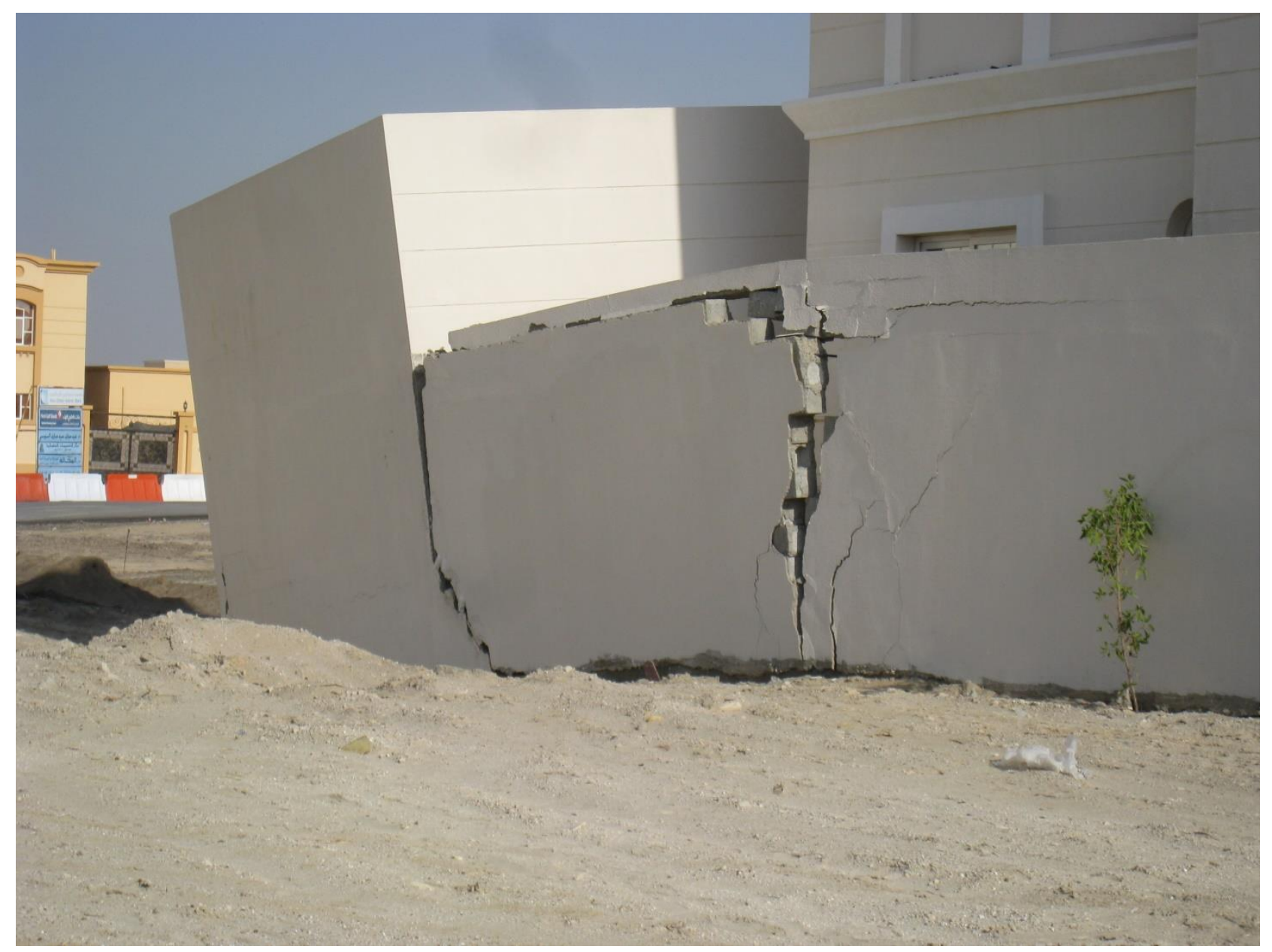

Fig.3 Tilted building and deformed boundary wall of a villa 


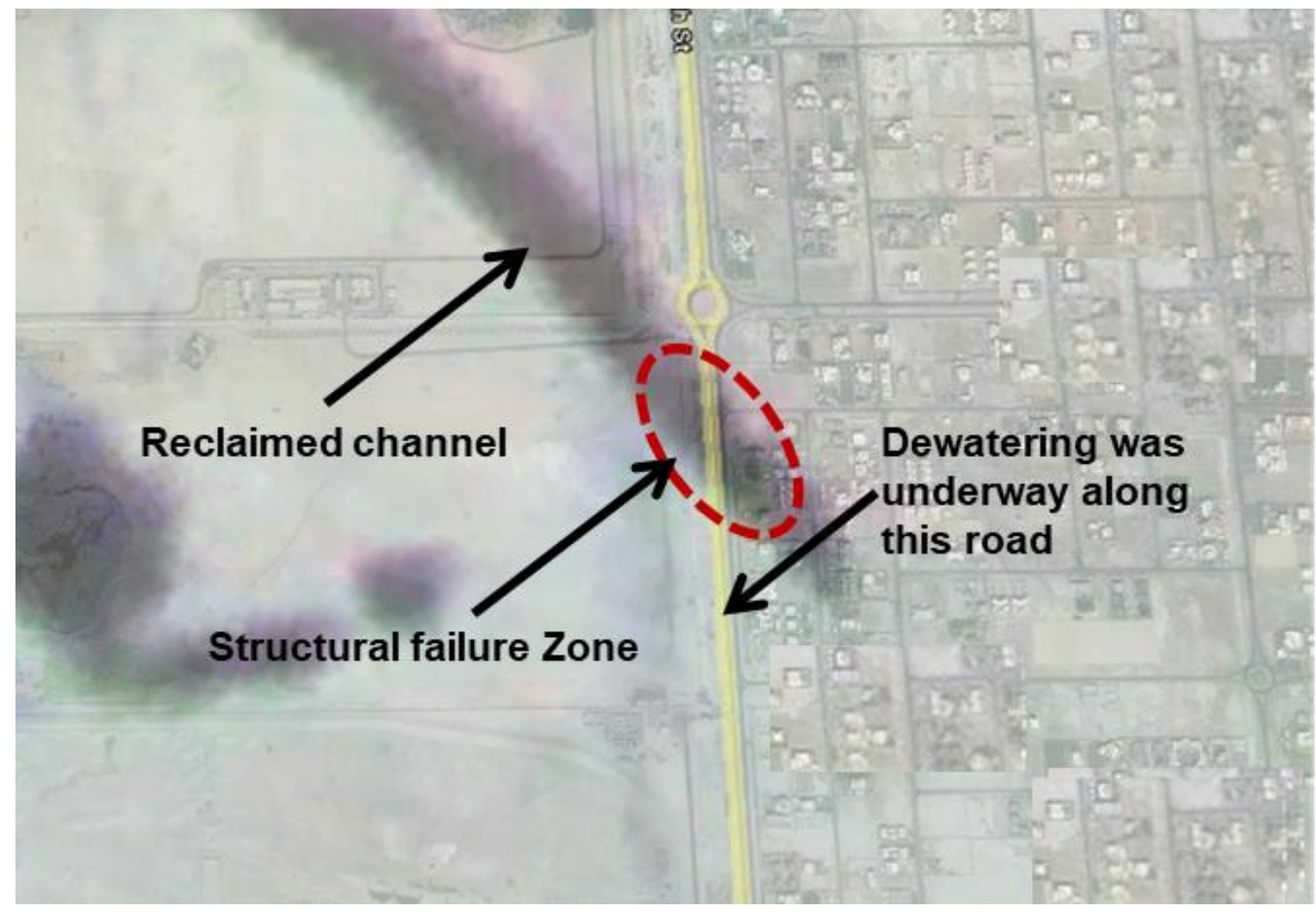

Fig.4 Historical aerial image of site in the mid 1980s 


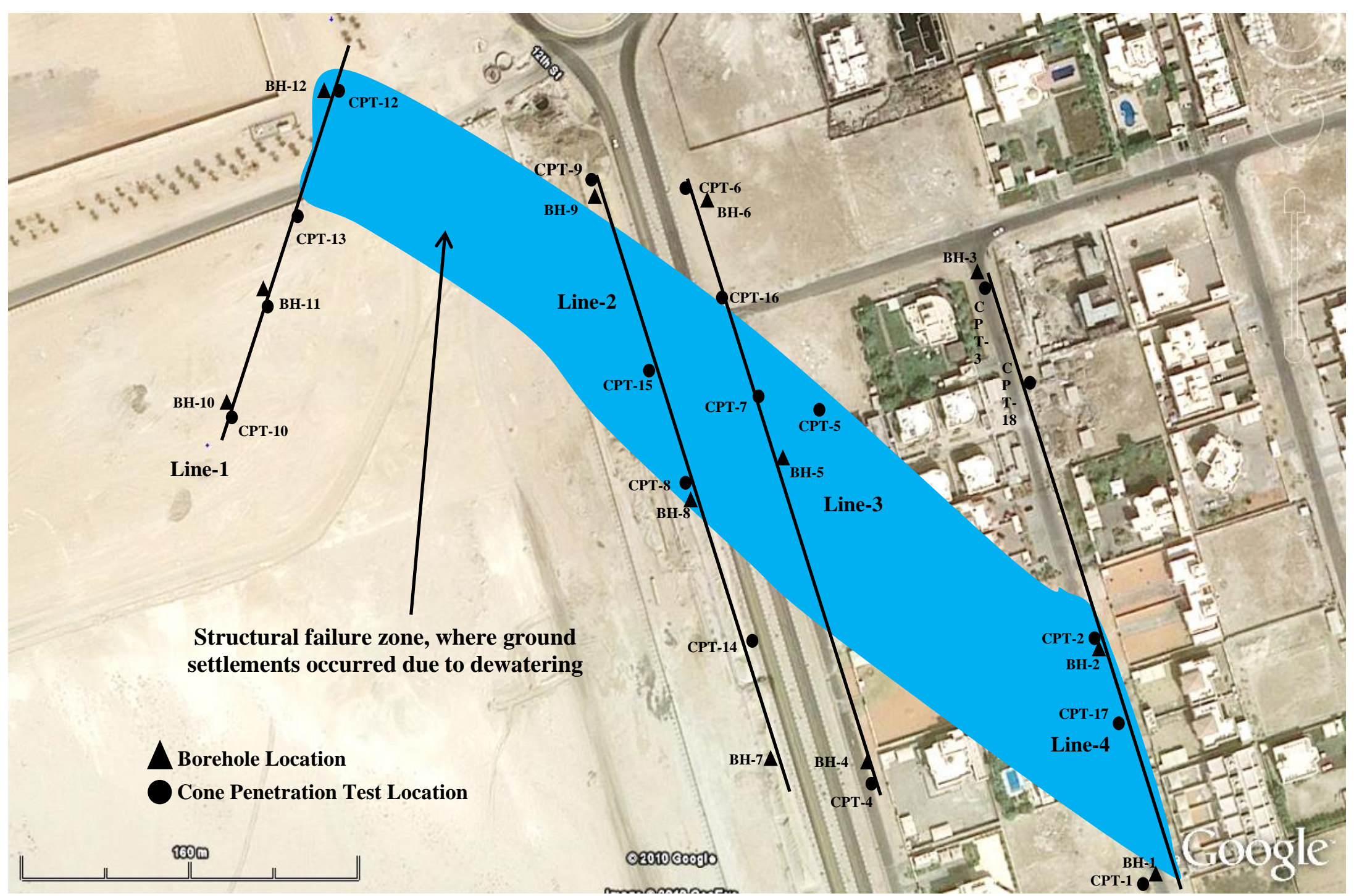

Fig.5 Distressed area and geophysical investigation lines (Lines 1-4) 


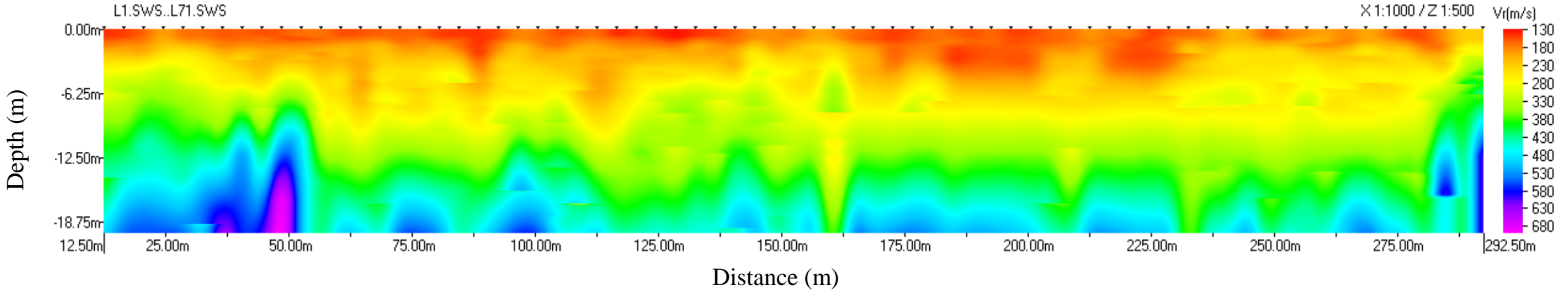

Fig.6 MASW survey result (Line 4)

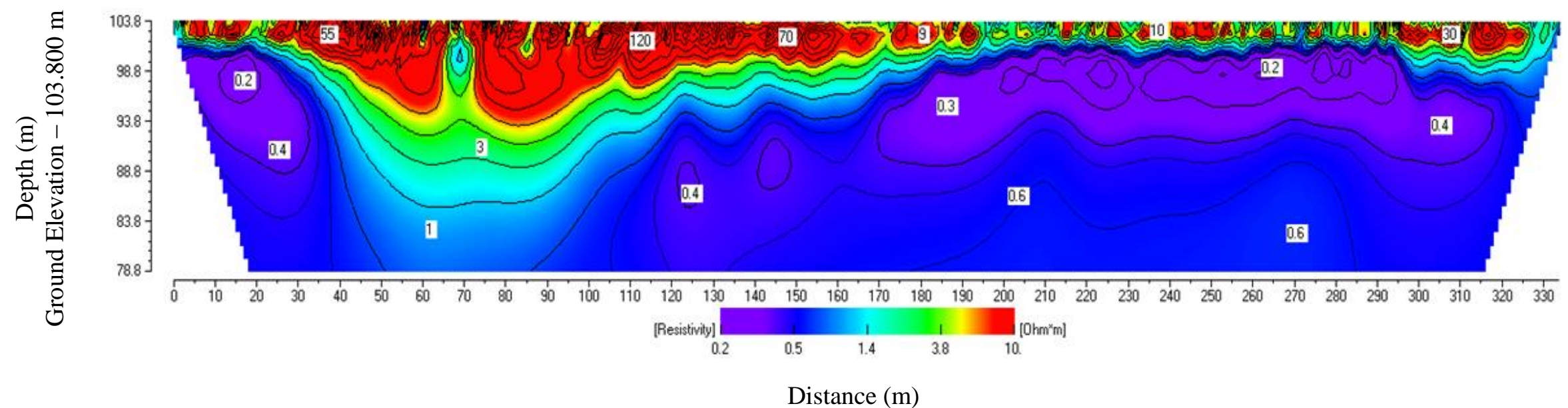

Fig.7 ERT survey result (Line 4) 


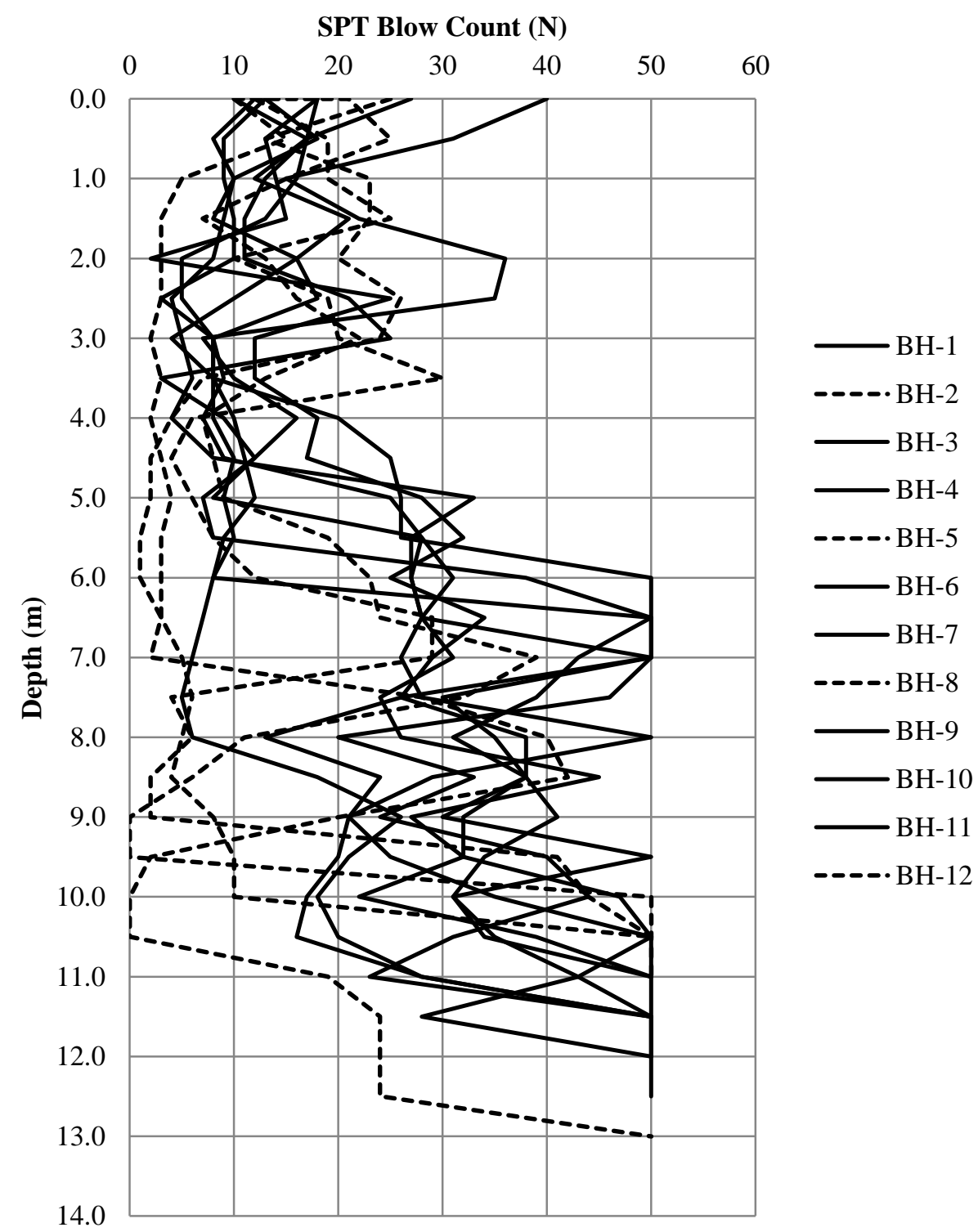

Fig.8 SPT blow counts versus depth

within structural failure zone; — outside structural failure zone) 


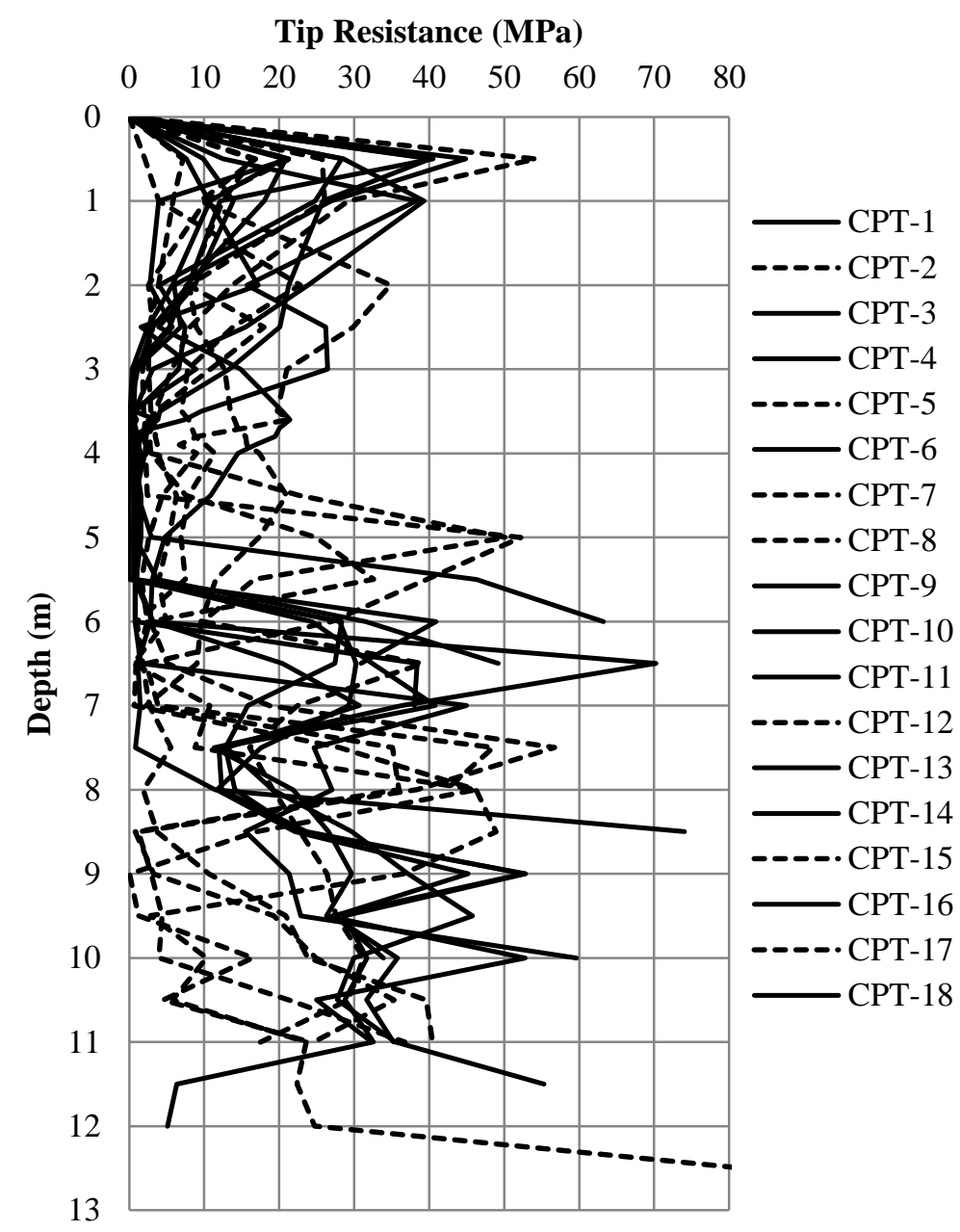

Fig.9 Cone tip resistance versus depth

(------ within structural failure zone; —_ outside structural failure zone) 
Table 1 General stratigraphy of the site within the structural failure zone

\begin{tabular}{|c|c|c|c|}
\hline $\begin{array}{c}\text { Depth } \\
(\mathbf{m})\end{array}$ & Description of soil & $\begin{array}{c}\text { Range of } \\
\text { SPT N- } \\
\text { Values }\end{array}$ & $\begin{array}{c}\text { Descriptive relative soil density } \\
\text { based on SPT / rock strength }\end{array}$ \\
\hline $0.0-6.0$ & Silty sand & $2-30$ & Very Loose to medium dense \\
\hline $6.0-8.0$ & $\begin{array}{c}\text { Gravel / clayey gravel / } \\
\text { clayey sand }\end{array}$ & $3-42$ & Very loose to dense \\
\hline $8.0-12.0$ & Silty sand & $2-50$ & Very loose to dense \\
\hline $12.0-17.0$ & $\begin{array}{c}\text { Mudstone (with gysum } \\
\text { inclusions) }\end{array}$ & - & Very weak to weak \\
\hline $17.0-20.0$ & Gypsum & - & Moderately weak to moderately strong \\
\hline
\end{tabular}

Table 2 General stratigraphy of the site outside the structural failure zone

\begin{tabular}{|c|c|c|c|}
\hline $\begin{array}{c}\text { Depth } \\
(\mathbf{m})\end{array}$ & Description of soil & $\begin{array}{c}\text { Range of } \\
\text { SPT N- } \\
\text { Values }\end{array}$ & $\begin{array}{c}\text { Descriptive relative soil density based } \\
\text { on SPT / rock strength }\end{array}$ \\
\hline $0.0-3.0$ & $\begin{array}{c}\text { Silty sand / silty gravelly } \\
\text { sand }\end{array}$ & $3-40$ & Very Loose to dense \\
\hline $3.0-6.0$ & $\begin{array}{c}\text { Clayey sand / very silty } \\
\text { sand }\end{array}$ & $3-25$ & Very Loose to medium dense \\
\hline $6.0-8.0$ & Silty sand & $26-50$ & Medium Dense to dense \\
\hline $8.0-12.0$ & Silty sand / very silty sand & $11-50$ & Medium Dense to dense \\
\hline $12.0-17.0$ & $\begin{array}{c}\text { Mudstone (with gysum } \\
\text { inclusions) }\end{array}$ & NA & Very weak to moderately weak \\
\hline $17.0-20.0$ & Gypsum & NA & Moderately weak to strong \\
\hline
\end{tabular}


Table 3 Comparison of weak layers from CPT and borehole data (samples along lines $2 \& 4$ )

\begin{tabular}{|c|c|c|c|c|c|c|c|c|c|c|}
\hline \multirow[b]{2}{*}{ Geophysical ID } & \multirow[b]{2}{*}{ BH-ID } & \multirow{2}{*}{$\begin{array}{l}\text { Depth of } \\
\text { Fill } \\
\text { Material } \\
\text { below EGL } \\
\text { (m) }\end{array}$} & \multicolumn{3}{|c|}{$\begin{array}{c}\text { Loose }(\mathrm{N} \leq 10) \text { Layer Depth Details } \\
\text { as per Boreholes }\end{array}$} & \multirow[b]{2}{*}{$\begin{array}{l}\text { Nearest } \\
\text { CPT } \\
\text { ID }\end{array}$} & \multicolumn{3}{|c|}{$\begin{array}{c}\text { Loose Layer Depth Details as per } \\
\text { nearest CPT-u } \\
\left.\text { (Tip Resistance, } \mathrm{q}_{\mathrm{c}}<10 \mathrm{MPa}\right)\end{array}$} & \multirow{2}{*}{$\begin{array}{l}\text { Inside / } \\
\text { Outside the } \\
\text { Anomaly or } \\
\text { Sand Bar }\end{array}$} \\
\hline & & & $\begin{array}{l}\text { Depth } \\
\text { of top of } \\
\text { layer(m) }\end{array}$ & $\begin{array}{c}\text { Depth } \\
\text { of } \\
\text { bottom } \\
\text { of layer } \\
\text { (m) }\end{array}$ & $\begin{array}{l}\text { Thickness } \\
\text { (m) }\end{array}$ & & $\begin{array}{l}\text { Depth } \\
\text { of top of } \\
\text { layer(m) }\end{array}$ & $\begin{array}{c}\text { Depth } \\
\text { of } \\
\text { bottom } \\
\text { of layer } \\
\text { (m) }\end{array}$ & $\begin{array}{l}\text { Thickness } \\
\text { (m) }\end{array}$ & \\
\hline \multirow{6}{*}{ Line-2 } & BH-7 & 3.00 & 3.00 & 6.50 & 3.50 & CPT-4 & 1.90 & 5.70 & 3.80 & Outside \\
\hline & BH-8 & 6.00 & 1.00 & 10.00 & 9.00 & СРТ-8 & $\begin{array}{l}2.10 \\
8.50\end{array}$ & $\begin{array}{c}7.50 \\
10.50\end{array}$ & 7.40 & Inside \\
\hline & BH-9 & 2.50 & 2.00 & 8.50 & 6.50 & CPT-9 & 1.90 & 6.00 & 4.10 & Outside \\
\hline & - & - & - & - & - & CPT-14 & 3.25 & 5.80 & 2.55 & Outside \\
\hline & \multirow{2}{*}{ - } & \multirow{2}{*}{ - } & \multirow{2}{*}{ - } & \multirow{2}{*}{ - } & \multirow{2}{*}{-} & \multirow{2}{*}{ CPT-15 } & 1.25 & 4.75 & \multirow{2}{*}{4.00} & \multirow{2}{*}{ Inside } \\
\hline & & & & & & & 6.50 & 7.00 & & \\
\hline \multirow{10}{*}{ Line-4 } & \multirow{2}{*}{ BH-1 } & \multirow{2}{*}{3.00} & \multirow{2}{*}{0.50} & \multirow{2}{*}{4.50} & \multirow{2}{*}{4.00} & \multirow{2}{*}{ CPT-1 } & 0.80 & 1.40 & \multirow{2}{*}{4.05} & \multirow{2}{*}{ Outside } \\
\hline & & & & & & & 1.80 & 5.25 & & \\
\hline & \multirow{3}{*}{ BH-2 } & \multirow{3}{*}{5.50} & 2.00 & 2.50 & & & & & & \\
\hline & & & 4.50 & 6.50 & 3.50 & СРТ-2 & 1.70 & 2.50 & 1.80 & Inside \\
\hline & & & 7.50 & 8.50 & & & 5.75 & 6.75 & & \\
\hline & BH-3 & 2.50 & 1.00 & 5.00 & 4.00 & CPT-3 & 1.70 & 5.90 & 4.20 & Outside \\
\hline & & & & & & & 0.00 & 4.50 & & \\
\hline & - & - & - & - & - & CPT-17 & 5.75 & 6.75 & 7.50 & Inside \\
\hline & & & & & & & 8.25 & 10.25 & & \\
\hline & - & - & - & - & - & CPT-18 & 2.00 & 5.50 & 3.50 & Outside \\
\hline
\end{tabular}

